IZA DP No. 10109

The Analysis of Prison-Prisoner Data Using Cluster-Sample Econometrics: Prison Conditions and Prisoners' Assessments of the Future

Horst Entorf

Liliya Sattarova

September 2016 


\title{
The Analysis of Prison-Prisoner Data Using Cluster-Sample Econometrics: Prison Conditions and Prisoners' Assessments of the Future
}

\author{
Horst Entorf \\ Goethe University Frankfurt \\ and IZA \\ Liliya Sattarova \\ Goethe University Frankfurt
}

\author{
Discussion Paper No. 10109 \\ September 2016
}

\author{
IZA \\ P.O. Box 7240 \\ 53072 Bonn \\ Germany \\ Phone: +49-228-3894-0 \\ Fax: +49-228-3894-180 \\ E-mail: iza@iza.org
}

\begin{abstract}
Any opinions expressed here are those of the author(s) and not those of IZA. Research published in this series may include views on policy, but the institute itself takes no institutional policy positions. The IZA research network is committed to the IZA Guiding Principles of Research Integrity.

The Institute for the Study of Labor (IZA) in Bonn is a local and virtual international research center and a place of communication between science, politics and business. IZA is an independent nonprofit organization supported by Deutsche Post Foundation. The center is associated with the University of Bonn and offers a stimulating research environment through its international network, workshops and conferences, data service, project support, research visits and doctoral program. IZA engages in (i) original and internationally competitive research in all fields of labor economics, (ii) development of policy concepts, and (iii) dissemination of research results and concepts to the interested public.
\end{abstract}

IZA Discussion Papers often represent preliminary work and are circulated to encourage discussion. Citation of such a paper should account for its provisional character. A revised version may be available directly from the author. 


\section{ABSTRACT}

\section{The Analysis of Prison-Prisoner Data Using Cluster-Sample Econometrics: Prison Conditions and Prisoners' Assessments of the Future}

The study investigates whether and how strong prison conditions contribute to the perceived propensity to recidivate after controlling for personal characteristics and criminal background. In order to combine different sources of information on personal characteristics of prison inmates and administrative prison data in an efficient way, we propose the use of matched prison-prisoner data and application of cluster-sample methods such as GEE (generalized estimating equations). Estimated average partial effects based on GEE and random-effects Probit modeling reveal that prison conditions show significant effects on the perceived likelihood of future reincarceration. Particularly, we find that inmates facing prison overcrowding show a reduced likelihood of recidivism.

JEL Classification: K40, C34, C52

Keywords: matched prison-prisoner data, perceived specific deterrence, recidivism, GEE

Corresponding author:

Horst Entorf

Goethe University Frankfurt

Faculty of Economics and Business Administration

Department of Applied Econometrics

Grüneburgplatz 1

RuW/PF 48

60323 Frankfurt am Main

Germany

E-mail: entorf@wiwi.uni-frankfurt.de 


\section{Introduction}

Ex-offenders show high rates of recidivism. In Germany, 56\% of released prisoners have been reconvicted within 4 years after release, and $42.3 \%$ have been convicted to a new prison sentence (Jehle 2009). In the US, these rates are even higher (Durose et al. 2014): Among state prisoners released in 30 states in 2005 about two-thirds $(67.8 \%)$ of released prisoners were arrested for a new crime within 3 years, and three-quarters (76.6\%) were arrested within 5 years. Hence understanding recidivism is an important issue of public policy. The impact of prisons has usually been studied in the economic and criminological literature on 'specific deterrence'. This strand of research considers the advantages and disadvantages of specific treatments of convicts, as, e.g., the fundamental question whether harsher or more lenient prison conditions are better suited to prevent future offending (see, among others, Katz et al. 2003, Chen and Shapiro 2007, Drago et al. 2011, and Mastrobuoni and Terlizzese (2014) in the field of economics). However, the literature neglects that the link between imprisonment and recidivism is composed of two parts: a first one directly related to prison influences, and a second one caused by factors outside prison bars such as problems of renewing adverse family relationships and other problems of reintegration and adjustment (Visher and Travis, 2003). Ignoring the composition of the effect easily results in wrong conclusions. For instance, coincidence of a crime curbing deterrent effect of prison conditions (that is, a "true" specific deterrence effect) and a crime increasing effect from adverse incentives after release would lead to blurred interpretations of the effect of prison conditions on recidivism. The contribution of this paper is to solely focus on the pre-release situation by using inmate survey data on the perceived risk of re-imprisonment as indicator of latent perceived specific deterrence, given prison conditions and after controlling for individual characteristics. Of particular interest in this context is prison overcrowding, as it might lead to less careful monitoring and less effective reintegration programs for inmates (see Franklin et al. 2006, Pritikin 2008 and Listwan et al. 2013).

Understanding recidivism of prison ex-inmates should benefit from efficiently linking the information of individual prisoner characteristics with data on the conditions within prisons where the inmate has served his sentence(s). Some previous literature on recidivism has already combined information on offenders and former prison experiences 1 , but so far there seems to be no generalizing framework which would allow to analyze matched prison-prisoner data sets in an efficient way, and which hints at suitable econometric methods and statistical properties of used estimators. A straightforward idea is to simultaneously include characteristics of matched prisons

\footnotetext{
${ }^{1}$ Drago et al. (2011) come close to the regression framework highlighted in our paper by using survey data of individuals released from Italian prisons and matching them with information on the facilities where the sentence was served.
} 
and prisoners which should reduce the potential bias arising from omitting observed and unobserved prison and prisoner characteristics in studies of recidivism. This idea borrows from labor economics, where this view has brought forward a beneficial literature on linked-employer datasets.: "...without linked data, there are obvious biases from not observing observables, and from not controlling unobservables" (Andrews et al. 2004). However, unlike linked-employer employee econometrics ${ }^{2}$ (see Abowd et al. 1999, for its statistical foundation), most realizations of prison-prisoner variables are not observed over time such that the elaborate least-squares framework approach based on "person" and "firm" effects proposed by Abowd et al. (1999) cannot be applied. Nevertheless, we will argue that the inclusion of information on prisoners as well as the prisons, in which they are/were incarcerated, is still of extreme significance for consistent and efficient econometric estimation. To substantiate our hypothesis, we will provide both theoretical and empirical evidence.

The econometric framework will be based on the literature on "grouped data", also known as "clustered data". The peculiarities of estimation strategies for these models, i.e. random-effects models and GEE (generalized estimating equations), have been described in detail by Wooldridge (2010) and Cameron, Trivedi (2005). The empirical analysis is based on German prison-prisoner data. It was collected via an inmate survey, which was conducted in a representative sample of 23 prisons across Germany. Fortunately not only the individual-level information was gathered during the survey, but the prison administration data on the correspondent prisons was collected as well. We will incorporate this source of information in our empirical model, and will work with the prison-prisoner data set.

Results show that estimated average partial effects based on nonlinear GEE and random-effects Probit modeling have high similarities, also with the linear LPM benchmark, but GEE parameters are estimated with higher accuracy. Empirical evidence concerning harshness of prison conditions are mixed: Overcrowding has a negative effect on the assessed likelihood of own future reincarceration, whereas a smaller size of a prison cell has a positive effect.

The paper is organized as follows. Section 2 describes the literature on prison conditions and recidivism. The econometrics of prison-prisoner data is presented in Section 3. Section 4 describes data and important covariates, while empirical results are discussed in Section 5. Section 6 concludes.

\section{Prison conditions and recidivism}

The propensity to recidivate depends on personal characteristics such as parental background, education, age and social capital, i.e. on 'criminogenic factors' known from the scientific literature, but the degree of recidivism is also related to the particular experience from being an

\footnotetext{
${ }^{2}$ The survey of Hamermesh (2007) provides an overview of various applications of employer-employee data, including topics of wage determination (Groshen 1991, Abowd et al. 1999), match quality and employment duration (Kiefer and Neumann 1979), social norms and peer effects (Durlauf 2002, Clark 2003), program evaluation (Crepon and Kramarz 2002, Oreopoulos 2006), etc.
} 
ex-offender. This makes former inmates different from other potential offenders who have not been influenced by idiosyncratic prison-specific factors such as rehabilitative programs, prison overcrowding, inmate violence, isolation, deaths in the offender's facility etc. (see Listwan et al. 2013 for a detailed survey of factors of 'prison strain'). The literature on "specific deterrence" lists advantages and disadvantages of specific treatments of convicts, as e.g. the fundamental question whether harsher prison conditions prevent recidivism or whether the opposite is true (see, among others, Sykes 2007, DeJong 1997, Pogarsky and Piquero 2003, Listwan et al. 2013, for contributions in criminology, and by Katz et al. 2003, Chen and Shapiro 2007, and Drago et al. 2011, in the field of economics). It can be concluded from recent surveys (see, Nagin et al. 2009, as well as Siegel 2012, and Listwan et al. 2013) that most papers find little or no evidence of a specific deterrent effect arising from the "pains of imprisonment" (Sykes 2007). Instead, some evidence even suggests that the likelihood of reoffending is increased (Listwan et al. 2013). Focusing on the effect of lenient prison conditions, Mastrobuoni and Terlizzese (2014) use data of a particular "open-cell prison" (Bollate) with strong efforts in rehabilitation programs and find a reduction in recidivism. However, as we argue in the introduction to this paper, empirical results might come from the negligence of the composite nature of the effect, with adverse post-release factors dominating the deterring prison-specific effect.

The focus of our paper is to study the pre-release prison situation and to study its effect on the perceived likelihood of recidivism. Personal inmate situations differ with respect to accommodation, ongoing servicing and reintegration programs, where prison sizes, cell size, the number of employees per prisoner and play important rules. Research by Drago et al. (2011), Franklin et al. (2006), Pritikin (2008) and Listwan et al. (2013) suggests that prison overcrowding can be considered a good indicator of adverse prison conditions, being related to less careful monitoring and less effective managing of inmates, and also to follow-up problems of inmate violence. Using Italian data, Drago et al. (2011) have found no significant effect or even an increased likelihood of subsequent (observed) recidivism rates.

The pure size effect (besides overcrowding) is rarely studied in criminometric research. As argued in Avio (1998) and Entorf et al. (2008), large prisons might provide correctional services and rehabilitative programs at a lower cost per prisoner than small prisons. Thus, as a consequence of cost-minimizing prison policies, prison inmates from larger facilities possibly benefit from more comprehensive rehabilitation services. On the other hand, descriptive evidence also reveals that economy-of-scale arguments have already led to a concentration of inmates with severe problems of drug or alcohol addiction in larger prisons. Given high recidivism rates of substanceabuse-related offenders, size effects might therefore be affected by selection problems unless the composition of the prison population is controlled for. In an empirical study using English prison statistics, Farrington and Nuttal (1980) found that, as the size of the institution increases, the average number of offenses per prison also tends to increase. However, after controlling for overcrowding they showed that size was not significantly correlated with their indicator of correctional 
effectiveness.

From the methodological and econometric point of view, Drago et al. (2011) come close to the regression framework highlighted in our paper by using survey data of individuals released from Italian prisons and matching them with information on the facilities where the sentence was served. Other papers such as Katz et al. (2003) rely on combining aggregate crime rates and prison conditions at state level, i.e. they only use indirect evidence, whereas we focus on individual data in the present paper. Some articles also differ because of diverging analytical methods: For instance, Chen and Shapiro (2007) apply regression discontinuity, and DeJong (1997) applies survival analysis. Pogarsky and Piquero (2003) base their evidence on an experiment with students (and do not use data on former prisoners).

\section{Estimation Strategy}

\subsection{Treatment of Grouped Prison-Prisoner Data}

Abowd et al. (1999) were among the first to introduce econometric modeling for linked employer-employee data set, which included information on individual characteristics of the employees as well as data on the companies' characteristics, in which they were employed. Thereafter, researchers paid significant attention to their suggested framework:

$$
y_{i t}=\mu_{y}+\left(x_{i t}-\mu_{x}\right) \beta+\theta_{i}+\psi_{P(i, t)}+u_{i t} .
$$

It includes the analysis of the data with respect to three dimensions: employers $(P)$, employees $(i)$, as well as dynamics of observed factors in time $(t)$. The specification requires the inclusion of individual $\theta_{i}$ and firm $P(i, t)$ random effects into the modeling equation, as the authors argue that the consistent estimation of the $\beta$ parameters is no longer possible without this inclusion. In this paper we follow the pattern suggested by Abowd et al. (1999) and introduce a prison-prisoner model. The so-called prison-prisoner data set incorporates information on prisoners as well as the prisons in which they are/were incarcerated. We will argue that the inclusion of both sets of data is of high significance for statistical properties of econometric estimation. To substantiate our hypothesis, we will provide both theoretical and empirical evidence.

The prison-prisoner data we use was collected in the years 2003 to 2004 via an inmate survey, which was conducted in 31 prisons across Germany (for more information on the survey structure, see Entorf, Meyer and Moebert 2008, and Entorf 2009). The individual data provided by the survey has been previously used in Entorf (2012), who analyzed the tendency of young offenders to recidivate; Entorf (2009) explored the relation of the recidivism tendency to the conditions of the labor market, in which convicts find themselves after they are released from prison. Fortunately not only the individual-level information was gathered during the survey, but also the prison administration data on the correspondent prisons was collected as well. In this paper, we will deepen the analysis of recidivism tendency. We will incorporate the second source of information - prison administration data on prisons in our model - and will work with the prison-prisoner data set. 
Although our model is in many ways consistent with the idea suggested by Abowd et al. (1999), it is also different which has to do with the specific nature of the observed data set properties as well as the nature of the dependent variable used in the paper. First, we observe crosssectional data on the prisons and their inmates, and the time variation is missing in our settings due to the data limitations as the survey was conducted only once. Second, the dependent variable of interest for our paper, assessment of recidivism, is binary in nature. The combination of these two distinct features of our data set directs our estimation strategies towards the binary estimation models for the clustered data.

Due to the elimination of the time dimension, our prison-prisoner data set resembles the structure of grouped data, also known as clustered data. Analysis of such data requires the use of clustering models. The peculiarities of estimation strategies for these models have been described in detail by Wooldridge (2010) and Cameron, Trivedi (2005).

We will use the following model for the analysis of grouped prison-prisoner data:

$$
E\left(y_{g m} \mid x_{g}, z_{g m}, c_{g}\right)=P\left(y_{g m}=1 \mid x_{g}, z_{g m}, c_{g}\right)=F\left(\alpha+c_{g}+x_{g} \beta+z_{g m} \gamma\right), m=1, \ldots, M_{g} ; g=1, \ldots, G
$$

At first glance, the presentation of the model resembles the one of the panel data model. There are, however, several differences between the two that should be considered in reading Eq. (2). Unlike the panel data, where the first index stands for an individual, the first index $g$ in our model represents a prison, whereas the second one $m$ stands for an individual. Therefore $y_{g m}$ is interpreted as an outcome ( 1 - self-assessed incline to recidivism, or 0 - otherwise) for an individual $m$, who serves his or her sentence at a prison $g$. The total number of prisons in the sample amounts to $G$, while the number of convicted at prison $g$ amounts to $M_{g} . x_{g}$ includes a set of explanatory variables, which are related to the characteristics of the prisons (prison administration data collected via the separate survey described above). $z_{g m}$ incorporates a set of individual-variant explanatory variables with information on each prisoner (collected via the survey of inmates). The corresponding parameters $\beta$ for prison variables and $\gamma$ for individual variables are assumed to be restricted in Eq. (2): $\beta_{m}=\beta$ are equal across different subgroups of inmates, and there are no differences in $\gamma_{g}=\gamma$ across various prisons either.

The unobserved cluster-specific effect $c_{g}$, introduced into the Eq. (2), is common to all prisoners at prison $g$. The inclusion of unobserved prison-specific effects is crucial for the estimation of our model. We assume heterogeneity across different prisons in terms of social atmosphere and internal factors, which are unobserved by the researcher, but may significantly influence the individual's attitude to the prison conditions and, consequently, affect his or her response to the prospective recidivism. Further assumptions on the distribution of $c_{g}$ and its relation to included independent variables are required for a consistent estimation, and will be provided separately for each model at a later stage.

The binary nature of the dependent variable implies estimation of the conditional probability $P\left(y_{g m}=1 \mid x_{g}, z_{g m}, c_{g}\right)$ of an inmate relapsing into criminal behavior after he or she is released 
from prison. Moreover, the dependent variable determines the nonlinear structure of the estimated model. Function $F(\cdot)$ accounts for this feature and specifies the form of the estimated conditional mean function. We focus on nonlinear GEE and Probit models, and we also consider the linear probability model (LPM) as linear benchmark. Assuming the long-running discussion on the choice between LPM or binary response models, and essential closeness of estimated average partial effects (APE) with both approaches (Angrist and Pischke 2009, and Wooldridge 2010, elaborate on this topic) we will consider both strategies for our estimation. Moreover, we will be able to check the robustness of the obtained results comparing the estimated APE across models. This brings us to the discussion of nonlinear models under comparison.

\subsection{Nonlinear Estimation Models: Pooled Probit, RE-Probit and GEE}

Nonlinear estimation procedures in the case of grouped data for the response probability equation, i.e.

$$
E\left(y_{g m} \mid x_{g}, z_{g m}, c_{g}\right)=P\left(y_{g m}=1 \mid x_{g}, z_{g m}, c_{g}\right)=\Phi\left(\alpha+c_{g}+x_{g} \beta+z_{g m} \gamma\right), m=1, \ldots, M_{g} ; g=1, \ldots, G
$$

are similar to the nonlinear models applied to the panel data setting. At this stage we replace the functional form $F(\cdot)$ of Eq. (2) with cdf of a normal distribution $\Phi(\cdot)$ in Eq. (3) We analyze the following types of models: RE-Probit, Pooled Probit and generalized estimating equations $(G E E)$ for the setting of grouped data with unobserved heterogeneity effects $c_{g}$ for prison $g$. These three models estimate the same type of model in Eq. (3), but address it with different technical approaches: Pooled Probit via Maximum Likelihood Estimation (MLE), RE-Probit via Conditional MLE (CMLE) and GEE with the help of Quasi-MLE (QMLE). Further in this section, we will elaborate on these estimation strategies, but we first list the set of assumptions required for a consistent estimation of parameters of interest $\beta$ and $\gamma$ for these techniques:

A.1 Assumption of strict exogeneity 4 .

- $D\left(y_{g m} \mid x_{g}, c_{g}\right)=D\left(y_{g m} \mid x_{g 1}, \ldots, x_{g M_{g}}, c_{g}\right)=D\left(y_{g m} \mid x_{g m}, c_{g}\right), \quad m=1, \ldots, M_{G}$

A.2 Distributional assumption of an error term:

- $u_{g m} \mid x_{g}, Z_{g}, c_{g} \sim N(0,1)$

A.3 Distributional assumption of unobserved heterogeneity effect:

- $c_{g} \mid x_{g}, Z_{g} \sim N\left(0, \sigma_{c}^{2}\right)$, where $\sigma_{c}^{2}$ is a variance of the unobserved group effect $c_{g}$

A.4 Distributional independence of an error term:

\footnotetext{
${ }^{3}$ The same intuition is applicable, for instance, to a logistic distribution function for binary response probability models.

${ }^{4} D(\cdot)$ represents distribution of a random variable
} 
- $\left\{u_{g 1}, \ldots, u_{g M_{g}}\right\}$ independent conditional on $\left(x_{g}, Z_{g}, c_{g}\right)$

Assumptions A.1-A.4 are necessary for the consistency of RE-Probit estimation. Particularly important is the distributional assumption within the cluster (A.4). It allows to identify $\alpha, \beta, \gamma$ parameters and $\sigma_{c}^{2}$ in Eq. (3) by means of CMLE. Yet this assumption imposes a structure, which is hardly attainable in a practical application. Unlike the case of RE-Probit, A.4 is redundant for the two other types of models. The fulfilment of assumptions A.1-A.3 is required for a consistent estimation of GEE, whereas A.2 and A.3 are sufficient for the consistency of the Pooled Probit. We will, hence, use the term "consistency" not with regard to the estimated parameters themselves, but with regard to the related APE (average causal change in the population mean of a response probability with respect to a change in the explanatory variable, e.g. $\left.x_{1}\right)$ :

$$
E\left[\frac{\partial P\left(y_{g m} \mid x_{g}, z_{g m}, c_{g}\right)}{\partial x_{g 1}}\right]=\beta_{1} E\left[\phi\left(\alpha+x_{g} \beta+z_{g m} \gamma+c_{g}\right)\right] 5
$$

It is this measure that remains the focus for the researcher in the nonlinear case, and not the value of the parameters itself. Following the assumptions listed above, all three methodologies produce consistent estimates of APE and can thus be compared to each other. Moreover, estimates obtained with the linear models represent the estimated APE and are, consequently, also comparable with the nonlinear estimates. We deliberately emphasize the importance of the APE measure, which unites all types of models, while the estimated parameters for the models in question have a different nature.

RE-Probit allows an estimation of subject-specific or, in case of grouped data, group-specific (GS) parameters vs. population-averaged (PA) parameters as in the Pooled-Probit and GEE case. We elucidate the differences in the interpretation of model estimates, which are:

- Group-Specific (GS) Estimates

$$
P\left(y_{g m}=1 \mid x_{g}, z_{g m}, c_{g}\right)=\Phi\left(\alpha_{G S}+c_{g}+x_{g} \beta_{G S}+z_{g m} \gamma_{G S}\right), m=1 \ldots, M_{g}
$$

- Population-Averaged (PA) Estimates

$$
P\left(y_{g m}=1 \mid x_{g}, z_{g m}, c_{g}=c\right)=\Phi\left(\alpha_{P A}+x_{g} \beta_{P A}+z_{g m} \gamma_{P A}\right), m=1 \ldots, M_{g}^{6}
$$

GS estimates allow to incorporate and identify $c_{g}$ for each subgroup in the model separately as in Eq. (5). PA estimates, in turn, estimate the response probabilities at specific values of $c_{g}$, e.g.

\footnotetext{
${ }^{5} \phi(\cdot)$ stands for pdf of a normal distribution.

${ }^{6}$ Zorn (2001) and Neuhaus et al. (1991) present a detailed comparison between two types of the estimated coefficients. A Stata FAQ webpage gives a numerical example to compare both types of estimates: http://www.stata.com/support/faqs/statistics/random-effects-versus-population-averaged/
} 
probabilities at the mean of $c_{g}=0$ as in Eq. (6). The relationship between both types of estimates is determined as:

$$
\alpha_{P A}=\frac{\alpha_{G S}}{\sqrt{1+\sigma_{c}^{2}}}, \beta_{P A}=\frac{\beta_{G S}}{\sqrt{1+\sigma_{c}^{2}}}, \gamma_{P A}=\frac{\gamma_{G S}}{\sqrt{1+\sigma_{c}^{2}}}
$$

Combining A.2 and A.3, we obtain: $\operatorname{Var}\left(v_{g m}\right)=\operatorname{Var}\left(u_{g m}+c_{g}\right)=\operatorname{Var}\left(u_{g m}\right)+\operatorname{Var}\left(c_{g}\right)=1+\sigma_{c}^{2}$, thus normalization of the parameters in Eq. (7) is achieved through scaling by the standard deviation of the model. As mentioned above, both types of models with GS and PA estimates deliver a consistent measure of APE, and its values are a priority for our analysis.

To obtain the correct inference the estimated covariance matrices for the RE-Probit, Pooled Probit and GEE models have to account for the clustered data structure. Shared conditions, social atmosphere, interactions between the prisoners in one prison imply both unobserved prisonspecific effects $c_{g}$ and the presence of a specific correlation structure among individuals within one prison. Hence, standard errors, which are robust to heterogeneity and, most importantly, robust to clustering, should be computed for the covariance matrix of the estimated parameters. This is achieved with the help of a robust sandwich estimator for the estimated covariance matrix. Since Pooled Probit and GEE deliver the GS estimates, both models can be compared in terms of their efficiency. GEE is beneficial in this comparison, as it attains additional efficiency gains through the choice of a flexible working correlation matrix in a combination with the sandwich robust estimator mentioned above (see Section 3.3 for more detail).

To sum up, the principal advantage of GEE methodology over the Pooled Probit model is that the former allows a more efficient estimation of the corresponding covariance matrix. Moreover, GEE does not impose any distributional assumptions within the cluster as the RE-Probit model. We thus choose GEE as the preferred estimation strategy for the analysis of prison-prisoner data in our paper.

\section{3. $G E E$}

A nonlinear approach GEE was first proposed by Liang and Zeger (1986). We will follow Zorn (2001), Ghisletta, Spini (2004) and Zorn (2006) to present this class of models. The GEE estimation is performed by QMLE procedure through solving $k$ "quasi-score" equations of the form?:

$$
Q_{k}\left(\beta_{G E E}\right)=\sum_{g=1}^{G} \frac{\partial \mu_{g}}{\partial \beta_{k_{G E E}}}\left(V_{g}\right)^{-1}\left(y_{g m}-\mu_{g}\right)=0,
$$

with $k$ being a number of included explanatory variables. Eq. (8) resembles the form of a derivative of a log-likelihood in case of MLE. To proceed with the estimation as in the MLE case, we first need to specify a particular distribution for the log-likelihood function. GEE addresses distributions of the linear exponential family (LEF): Gaussian (normal), inverse Gaussian,

\footnotetext{
${ }^{7}$ Parameter $\beta_{G E E}$ in the GEE presentation includes parameters on both individual-variant and -invariant explanatory variables: $\beta_{G E E} \equiv\left(\beta^{\prime}, \gamma^{\prime}\right)$. Vector $x_{g}$, in turn, incorporates both group-variant and -invariant explanatory variables.
} 
Bernoulli/Binomial, Poisson, Negative Binomial or Gamma distribution. A distinct feature of these distributions is that a conditional variance of the distribution is formed via the pre-specified conditional mean function:

$$
E\left(y_{g m} \mid x_{g}\right)=\mu_{g}=g^{(-1)}\left(x_{g} \beta_{G E E}\right) \quad \Rightarrow \quad \operatorname{Var}\left(y_{g m} \mid x_{g}\right)=v\left(\mu_{g}\right) \lambda .
$$

The mean function $\mu_{g}$ is specified through a link function $g^{-1}(\cdot)$, which may be represented as identity, log, logit, probit or power (k) function. The variance $v\left(\mu_{g}\right)$ is formed as a function of the chosen mean $\mu_{g}$, the form of the variance depends on the type of the chosen LEF distribution. The dispersion or scale parameter $\lambda$, included in the final variance presentation in Eq. (9), allows the variance of the model to deviate from the variance assumed by the LEF, which may result in an overdispersion if $\lambda>1$, and an underdispersion if $\lambda<1$. The choice of the appropriate mean function is important for the GEE estimator. In our model, the bivariate nature of the dependent variable intuitively leads to the choice of a probit link function, $g^{(-1)}=\Phi(\cdot)$, and a binomial distribution for the likelihood for the variance formation. Thus the related conditional mean and variance of the model have the following forms:

$$
E\left(y_{g m} \mid x_{g}\right)=\Phi\left(x_{g} \beta_{G E E}\right)=\mu_{g}, \operatorname{Var}\left(y_{g m} \mid x_{g}\right)=\lambda \cdot \Phi\left(x_{g} \beta_{G E E}\right)\left(1-\Phi\left(x_{g} \beta_{G E E}\right)\right)=\lambda \cdot \mu_{g} \cdot\left(1-\mu_{g}\right) .
$$

The variance $V_{g}$, used for the quasi-score function in Eq. (8), is formed as $V_{g}=A_{g}^{1 / 2} R_{g}(\rho) A_{g}^{1 / 2}$, where $A_{g}$ is a diagonal matrix with elements specified by elements of the variance $\operatorname{Var}\left(y_{g m} \mid x_{g}\right)$ and $R_{g}(\rho)$ being a working correlation matrix. It should be noted that $V_{g}$ serves as a weighting matrix for the estimation model in Eq. (8); therefore, GEE serves as an application of the weighted multivariate nonlinear least squares (WMNLS) approach. The introduction of $R_{g}(\rho)$ into the variance form allows to incorporate assumptions about the correlation structure within the cluster $g$. The name "working" implies that the matrix may not contain the true conditional correlation coefficients. Nevertheless, its misspecification does not influence the consistency of the estimated variance of the model.

The matrix $R_{g}(\rho)$ may be chosen as:

- identity - no correlation in the cluster

- exchangeable - same correlation $\rho$ among all individuals in the cluster

- autoregressive - correlation of $\rho^{|t-s|}$ for the individuals $t$ and $s$ in the cluster

- unstructured - empirical correlation in the cluster, computed by means of observed data.

The flexible choice of the correlation structure within the cluster makes GEE an appealing estimation method. The implied correlation structure and the unstructured form, in particular, correct the estimated variance of the model, and improve efficiency. Yet one should be cautious with the specification of the working correlation matrix. The intuitive choice of the unstructured correlation 
form increases the number of estimated parameters for the model: any pairwise correlation within the group has to be estimated. This can, in turn, destabilize the optimizing procedure. The application of the simpler correlation structure requires estimation of fewer parameters. At the same time, the property of the consistently estimated covariance matrix in the presence of a misspecified working matrix guarantees the correct inference for the model. Therefore, more restrictive correlation forms could still be considered as a better solution for the model.

Once conditional mean, variance and working correlation matrix are specified, one may proceed with the solving procedure for the quasi-score equations in Eq. (8). Computed standard errors for estimated GEE parameters have to be corrected for clustering using robust standard errors estimators analogous to the estimators proposed by White (1980). The whole procedure leads to the most valuable feature of GEE: it produces consistent estimates of the APE of interest and consistent estimates of corresponding standard errors even in the case of a potentially misspecified form of chosen variance $V_{g}$ or $R_{g}(\rho)$ (Lian, Zeger 1986, Zorn 2001, Wooldridge 2010). Thus: "GEE becomes an indispensable tool to ensure our inference is robust to misspecification of the serial correlation structure we adopt." (Wooldridge 2010)

It is worth mentioning that mean and variance of the model are both functions of $\beta_{G E E}$ parameters and both enter the quasi-score function (see Eq. (8) and Eq. (9)). Despite the fact that GEE does not model the group-specific effects $c_{g}$ directly, the clustered structure of the data is still incorporated into the estimated parameters through robust standard errors and a working correlation matrix. To sum up, GEE produces consistent estimates of the APE, incorporates robustness to any sort of correlation in the cluster standard errors and gains efficiency through the use of the working correlation matrix. It will, therefore, be chosen as the preferred estimation strategy in this paper.

\section{Data Description}

The data set originates from a survey of prison inmates who were interviewed during the time period 2003 to 2004, and a second simultaneous survey addressed to the management and administration units of visited prisons. The survey design followed a two-stage approach that combined stratified and random sampling (see Entorf, Meyer and Moebert 2008, for details on the survey). In a first step, prisons were chosen such that the sample of prisons provides a representative sample of the population of all prisons in Germany. The stratification scheme was realized along the criteria 'region / state' (i.e. regions represented by 'Bundesland') as well as the criteria 'number of prisons per 100,000 state inhabitants', 'prisoners per 100,000 state inhabitants', 'share of prisoners convicted according to adult (juvenile) penal law' and 'share of prisoners with a term equal and more (less than) two years'. The second step consisted of a random draw from the population of selected prisons. The survey was organized and performed by a team of researchers from Darmstadt University, the design and the wording of the questionnaire was accomplished in joint cooperation with criminologists and practitioners. As might be assumed from the delicate issue of interviewing prisoners behind bars, administrative barriers were quite high. For instance, interviews were only 
possible upon approval of the Departments of Justice of the respective states, and it was necessary to achieve compliance of local prison managers, to collect signed informed consents of prisoners who were selected to be interviewed, and it took lasting organizational work and cooperation with prison staff until the questionnaire could be finally handed over to the interviewee (who, of course, then was allowed to respond without presence of any guard or control). Some additional informal interviews with judicial employees at visited prisons indicated that participation in the survey might have been more likely for the more 'active' and cooperative group of prisoners, while the more inactive and apathetic part of the prison population preferred to stay in their cell (see Entorf et al. 2008, for details).

We exclude the juvenile prisons and inmates convicted under juvenile law from the analysis to avoid misinterpretation of obtained results. In Germany, adolescents under the age of 18 are generally convicted under juvenile law, adolescents between the age of 18 and under 21 years may be either convicted under juvenile or adult penal law, dependent on the courts' impression of the moral and mental personal development of the adolescent at the time of the act. In order to study individual recidivism under the same legal and institutional conditions, we restrict the analysis to conditions limited to adult prisoners. Additionally, we restrict our analysis to 1,124 individuals with available information on prison conditions which is the case for 23 prisons (the reported reason for non-participation of the remaining eight prison management units was overload of administration). The variable of interest is 'assessment of recidivism'. It is constructed from the response to the survey question "Could it occur that after your release from custody you come into conflict with the law and end up in prison? Tick your assessment on the 5-point scale, whereby a '1' stands for 'no, never', and a '5' stands for 'absolutely certain'. "8 8 The binary variable "assessment of recidivism" summarizes categories 3 to 5, i.e. it takes the value 1 if the respondent expresses serious concerns of becoming a recidivist ( 0 otherwise; this definition follows Entorf 2009) According to this definition, descriptive statistics from Table 1 reveal that $25 \%$ are rather pessimistic with respect to their future legal perspectives outside prisons. This is consistent with the re-incarceration rate of $23.4 \%$ of former prison inmates for the years 2004-2007 (according to the official German recidivism statistics in Jehle et al. 2010, p. 47-48)

The data includes a large set of control variables and is represented by two major blocks. The first block covers information on the prison where the convict serves his or her sentence. The second block provides information on individual characteristics of inmates. Descriptive statistics are listed in Table 1. It seems appropriate to provide some remarks on important covariates. Based on the literature on specific deterrence, at the prison level we cover prison conditions such as the degree of overcrowding, prison size, staffing (measured as number of employees per prisoner), and cell size (single occupancy). Interviewed administrations report that the average capacity

\footnotetext{
${ }^{8}$ The survey was distributed in either German or Turkish, Serbo-Croatian, Russian, Polish and English language.

${ }^{9}$ Given the rarely ticked categories 4 and 5 (only $1 \%$ and $2 \%$, respectively, gave this response), summarizing categories seems to be a reasonable approach to prevent misinterpretation of subjective survey questions and avoids problems arising from sparsely filling in survey categories.
} 
Table 1: Prison-Prisoner Descriptive Statistics

\begin{tabular}{|c|c|c|c|c|c|}
\hline & \# of observations & Mean & SE & Min & Max \\
\hline \multicolumn{6}{|l|}{ Dependent Variable } \\
\hline Assessment of recidivism & 1124 & 0.25 & 0.43 & 0 & 1 \\
\hline \multicolumn{6}{|l|}{ Prison } \\
\hline Overcrowding level & 23 & -0.01 & 0.07 & -.1996 & .1184 \\
\hline \# of prisoners in 100 & 23 & 5.71 & 3.57 & .68 & 12.5 \\
\hline \# of employees per prisoner & 23 & 0.49 & 0.13 & .2879 & .8057 \\
\hline Prison cell size (single occupancy), $m^{2}$ & 23 & 8.76 & 1.12 & 5.9 & 10.6 \\
\hline \multicolumn{6}{|l|}{ Prisoner } \\
\hline Criminal family (childhood) & 1124 & 0.20 & 0.40 & 0 & 1 \\
\hline Parents separate (childhood) & 1124 & 0.19 & 0.39 & 0 & 1 \\
\hline Small municipality (childhood) & 1124 & 0.39 & 0.49 & 0 & 1 \\
\hline Criminal family members & 1124 & 0.15 & 0.35 & 0 & 1 \\
\hline Criminal friends & 1124 & 0.36 & 0.48 & 0 & 1 \\
\hline Values: social contacts & 1124 & 0.48 & 0.50 & 0 & 1 \\
\hline Married & 1124 & 0.19 & 0.40 & 0 & 1 \\
\hline Frequent contact with partner & 1124 & 0.53 & 0.50 & 0 & 1 \\
\hline Age & 1124 & 36.37 & 10.91 & 18 & 68 \\
\hline Male & 1124 & 0.86 & 0.35 & 0 & 1 \\
\hline Nationality $=$ German & 1124 & 0.84 & 0.37 & 0 & 1 \\
\hline Education = Abitur & 1124 & 0.10 & 0.29 & 0 & 1 \\
\hline No professional education & 1124 & 0.34 & 0.47 & 0 & 1 \\
\hline Recidivist (prison sentence) & 1124 & 0.30 & 0.46 & 0 & 1 \\
\hline Age at first crime & 1124 & 25.15 & 11.40 & 12 & 68 \\
\hline Alcohol/drug addiction & 1124 & 0.33 & 0.47 & 0 & 1 \\
\hline Crime $=$ theft & 1124 & 0.22 & 0.41 & 0 & 1 \\
\hline Crime $=$ drug deal/consumption & 1124 & 0.20 & 0.40 & 0 & 1 \\
\hline Crime $=$ fraud & 1124 & 0.21 & 0.41 & 0 & 1 \\
\hline Crime $=$ robbery & 1124 & 0.12 & 0.32 & 0 & 1 \\
\hline Crime $=$ sexual offense & 1124 & 0.11 & 0.31 & 0 & 1 \\
\hline Crime $=$ murder & 1124 & 0.09 & 0.29 & 0 & 1 \\
\hline Crime $=$ assault & 1124 & 0.16 & 0.37 & 0 & 1 \\
\hline Crime $=$ other crime & 1124 & 0.19 & 0.39 & 0 & 1 \\
\hline
\end{tabular}


utilization is $99 \%$, i.e. average overcrowding is $-0,01$. Overall, overcrowding ranges between $-20 \%$ and $+12 \%$. The prison size ranges between 68 and 1,250 inmates. Also the range of employees per inmate has a rather large variation, ranging between 0.29 and 0.80 . On average, there is a value of 0.49 employee per inmate, i.e. about two inmates per employee. The average cell size is 8.76 $\mathrm{m}^{2}$, and ranges between $5.9 \mathrm{~m}^{2}$ and $10.6 \mathrm{~m}^{2}$.

The individual personal level data includes information on the socioeconomic background, such as sex, marital status and nationality, but also on social capital, the educational level, on health conditions, childhood and criminal background of relatives and friends. Growing up within a criminal parental background (under the age of 15 years) is captured by the dummy variable "criminal family (childhood)". It documents any criminal record within the "Elternhaus" (i.e. the parental home), i.e. of father, mother, brothers, or other close relatives. This criminal background applies to $20 \%$ of all respondents. The variable "criminal family members" covers the same feature, but at the time the survey took place (15\% report this to be true). A higher share of (formerly and formally convicted) criminals (36\%) can be found among the peers at this time, see "criminal friends", i.e. the dummy variable indicating criminal friends. The existence of social bonds due to close interaction with spouses and partners are represented by "married" and "frequent contact with partner" (at least once a week). Only $19 \%$ of inmates are married, but $53 \%$ of inmates report that they have contact with partners more than once a week. A ratio of $48 \%$ also report that they consider socializing and cultivating contacts as "very important" (category 4 in the range between 1 = "not important" to 4 = "very important"): see "values: social contacts". Human capital background is represented by the dummy variable "Abitur", which is equal to one for those who achieved the highest German educational level (which would allow to attend universities). The share (10\%) is about half of the one of the German resident population. Even though selfselection mechanisms might have favored the presence of more active and possibly more educated respondents, comparisons with official statistics of the German resident population confirm a relatively poor human capital background for the majority of prison inmates, as can also be seen from the share of $34 \%$ responding not to have completed any professional education ("no professional education"). One of the most severe problems (not only) of German prisons is the high proportion of inmates being addicted to alcohol, illicit drugs or both: $33 \%$ respond that they consider themselves to be addicted or 'having serious problems' with alcohol or drugs. This high percentage corresponds with the large share of $20 \%$ of inmates being convicted due to drug offences (drug dealing or consumption), not counting convictions indirectly related to drug or alcohol abuse such as theft, or violent acts which are committed under the influence. Further control variables refer to gender, age, and the crimes committed by inmates. The largest groups consist of theft (22\%), fraud $(21 \%)$ and drug offences (20\%) (note that the sum exceeds $100 \%$ as inmates might be committed for more than one single crime). About one third of inmates $(30 \%)$ has served at least one former prison term (see "recidivist"). As can be seen from the ratio of $86 \%$, the prison population is mainly male. The age distribution is limited to inmates above 18 years, the average age is 36 
years. The list of covariates also includes "age at first crime", i.e. the individual age at the time of the first conviction in a court or in terms of a punitive educational measure (average age $=25$ years).

\section{Empirical Evidence}

\subsection{Estimation Results}

The econometric modeling of prison-prisoner data has been performed by applying the nonlinear models random-effects (RE) Probit and Generalized Estimation Equations (GEE), as well as the Linear Probability Model (LPM). We aim to test the hypothesis that the self-assessed likelihood of recidivism depends on prison conditions, which are covered by the level of overcrowding, prison size, number of employees per prisoner, and the size of prison cells. As outlined in Section 3.2. we consider consistency with regard to the estimated APE and not the value of the estimated parameter itself. Strict exogeneity (see A.1) is one of the assumptions required for LPM, RE-Probit and GEE estimators to be consistent. This assumption implies that the behavior of a prisoner is not influenced by the characteristics of his fellow-inmates, once we controlled for prison characteristics and unobserved heterogeneity. This assumption presumably holds: information on criminal behavior (mostly determined in the past) has exogenous nature across individuals, prisoners were not in contact with each other before the imprisonment. Moreover it needs to be pointed out that we treat prison conditions as variables of interest. With respect to these variables the exogeneity assumption is reasonable, because imprisonment takes place according to strict state-specific judicial competencies ("Vollstreckungsplan"10). The general rule is that imprisonment should take place in the region where the criminal has had his main place of residence. Further selection (within regions) separates recidivists from non-recidivists, males from females, and long-term imprisoned from short-term sentenced. These peculiarities will be considered by including dummy variables on recidivism, gender and type of crime as control variables. Prisoners have been randomly preselected from the alphabetical list of all prisoners of selected prisons, but there might be concerns that no-shows were less motivated and substantially different from survey participants. We have checked this problem below (Section 5.2) and we found no statistical evidence for non-random selection.

Regarding control variables, we follow the applied econometrics literature and assume conditional mean independence (Stock 2010), which implies that once we control for further individual characteristics and unobserved heterogeneity, the conditional mean of the error term no longer depends on prison conditions. Control variables are included in order to achieve that variables of interest are conditionally uncorrelated with the error term such that the estimated coefficients on prison conditions have a causal interpretation. Coefficients do not necessarily have any causal

\footnotetext{
${ }^{10}$ See, e.g., the rules for the states Hessen (https://www.vollstreckungsplan-hessen.de/vollstrpl_ hessen.pdf) and Baden-Württemberg (http://www.vollstreckungsplan-bw.de/pls/vp/vp_index).
} 
meaning, because they may be correlated with the error term. However, controls are required to be "good controls" in the sense that we can think of them as having been fixed at the time the variables of interest were determined (Angrist and Pischke 2009, p. 64).

The basic model (Table 2, equations 1 to 3 ) is restricted to individual characteristics. It includes several personal attributes such as age, gender, nationality and educational background as well as information on health status (alcohol/drug addiction). Extensive characterizations of the criminal personality type are controlled for which cover reasons of imprisonment (theft, assault, fraud, murder etc.), a recidivist dummy and age at first crime. The next estimation model (Table 2 , equations 4 to 6) adds parental background factors which map the time of the childhood of prisoners. Here we consider the influence of the criminal background of close relatives (in particular of parents), separation of parents and a dummy for growing up in a small municipality. Finally, we include familial and social capital factors which have been cumulated during a prisoner's life time (Table 2, equations 7 to 9). These are "criminal family members", "delinquent peers", "values: social contacts", "married" and "frequent contact with partner". As regards the definition of "good" and "bad" controls, the latter specification has the potential to include some bad ones, for instance because interactions with partners and family members might have been affected by the future prospect, assessment and expectations of inmates. However, although we consider this specification as somewhat more critical, we keep it in order to analyze the robustness of the coefficients on the variables of interest.

Results from applied methods may differ due to a lacking validity of respective assumptions and for reasons of efficiency. We expect the GEE methodology to deliver the most efficient results (through the use of the working correlation matrix). Thus, GEE estimated standard errors are expected to be lower compared to the RE-Probit case. Due to the strong assumption of distributional independence of the error term, i.e. A4, assumptions for consistency of RE-Probit APE are more restrictive and seem to be less feasible in practice. We therefore anticipate differences between the estimated GEE and RE-Probit APEs.

A comparison of the RE-Probit and GEE results shows the expected differences with respect to standard errors: GEE parameters seem to be estimated with higher accuracy, also the overall chi-square of GEE estimates exceeds the one of RE-Probit by a large amount. Parameter values of significant estimates also differ, but not much. Inspecting results of Table 2 (and using model (5) as a specification restricted to "good" controls), the largest difference occurs for the effect of overcrowding, where the APE of RE-Probit is -0.52, and application of GEE leads to -0.48 (LPM: -0.58). In general, results are very close to each other. This also holds for comparisons with the linear LPM.

Besides "number of inmates per prison" and "overcrowding", we also consider potential deficiencies in monitoring, managing, psychosocial care etc. by using "number of employees per prisoner". Results show a significant negative effect from overcrowding on self-reported likelihood of recidivism. A coefficient of -0.5 implies that a 10 percentage-point change of overcrowding 
(i.e. from, say, $90 \%$ to $80 \%$ ) would on average ceteris paribus decrease the assessed likelihood of recidivism by 0.05 , i.e. 5 percentage points. At first glance, this result differs, for instance, from the one in Drago et al. (2011) and others, who found no significant effect or even an increased likelihood of subsequent realized recidivism rates. To interpret reported expectations in the face of given prison conditions, it may be helpful to highlight the consequences of prison overcrowding. As pointed out in more detail elsewhere (Franklin et al. 2006, Pritikin 2008, Listwan et al. 2013), prison overcrowding can lead to less careful monitoring, less careful managing of inmates with health and psychological problems or who otherwise pose a threat of violence. Overcrowding also means fewer resources (for training, rehabilitation) available to each inmate, which can magnify frustration and uncertainty about the future (but note that we control for the number of employees per inmate). It seems thus to be reasonable that inmates disapprove of their current situation and express their goal and subjective expectation that they will (or would like to) avoid it in the future. This expectation may be partly biased by wishful thinking, and it does not prevent that some exconvicts, contrary to their beliefs, actually become recidivists after their release, just because their prison conditions have been deficient. Thus, our results do not necessarily contradict those of 
Table 2: Determinants of Prisoners' Assessment of Future Recidivism

\begin{tabular}{|c|c|c|c|c|c|c|c|c|c|}
\hline & $\begin{array}{c}(1) \\
\text { LPM }\end{array}$ & $\begin{array}{c}\text { Individual } \\
\text { (2) } \\
\text { RE-P }\end{array}$ & $\begin{array}{c}(3) \\
\text { GEE }\end{array}$ & $\begin{array}{c}(4) \\
\text { LPM }\end{array}$ & $\begin{array}{l}\text { ndowment } \\
\text { (5) } \\
\text { RE-P }\end{array}$ & $\begin{array}{c}(6) \\
\text { GEE }\end{array}$ & $\begin{array}{c}(7) \\
\text { LPM }\end{array}$ & $\begin{array}{l}\text { cial Capital } \\
\text { (8) } \\
\text { RE-P }\end{array}$ & $\begin{array}{c}(9) \\
\text { GEE }\end{array}$ \\
\hline Overcrowding level & $\begin{array}{l}-0.578 * * * \\
(0.147)\end{array}$ & $\begin{array}{c}-0.526^{* *} \\
(0.210)\end{array}$ & $\begin{array}{c}-0.477 * * * \\
(0.161)\end{array}$ & $\begin{array}{l}-0.577 * * * \\
(0.150)\end{array}$ & $\begin{array}{c}-0.523 * * \\
(0.210)\end{array}$ & $\begin{array}{c}-0.478 * * * \\
(0.163)\end{array}$ & $\begin{array}{c}-0.557 * * * \\
(0.157)\end{array}$ & $\begin{array}{c}-0.508 * * \\
(0.206)\end{array}$ & $\begin{array}{c}-0.488 * * * \\
(0.175)\end{array}$ \\
\hline \# of prisoners in 100 & $\begin{array}{l}0.012 * * * \\
(0.003)\end{array}$ & $\begin{array}{l}0.012 * * * \\
(0.004)\end{array}$ & $\begin{array}{l}0.014 * * * \\
(0.003)\end{array}$ & $\begin{array}{l}0.012 * * * \\
(0.003)\end{array}$ & $\begin{array}{l}0.012 * * * \\
(0.004)\end{array}$ & $\begin{array}{l}0.013 * * * \\
(0.003)\end{array}$ & $\begin{array}{l}0.009 * * \\
(0.003)\end{array}$ & $\begin{array}{l}0.010^{* *} \\
(0.004)\end{array}$ & $\begin{array}{l}0.011 \text { *** } \\
(0.003)\end{array}$ \\
\hline \# of employees per prisoner & $\begin{array}{c}0.017 \\
(0.098)\end{array}$ & $\begin{array}{c}0.020 \\
(0.115)\end{array}$ & $\begin{array}{c}0.056 \\
(0.088)\end{array}$ & $\begin{array}{c}0.018 \\
(0.096)\end{array}$ & $\begin{array}{c}0.023 \\
(0.116)\end{array}$ & $\begin{array}{c}0.058 \\
(0.089)\end{array}$ & $\begin{array}{c}0.017 \\
(0.101)\end{array}$ & $\begin{array}{c}0.021 \\
(0.114)\end{array}$ & $\begin{array}{c}0.047 \\
(0.095)\end{array}$ \\
\hline Prison cell size & $\begin{array}{c}-0.018 * * \\
(0.008)\end{array}$ & $\begin{array}{c}-0.017 \\
(0.011)\end{array}$ & $\begin{array}{c}-0.017 * * \\
(0.008)\end{array}$ & $\begin{array}{c}-0.018 * * \\
(0.008)\end{array}$ & $\begin{array}{r}-0.017 \\
(0.011)\end{array}$ & $\begin{array}{c}-0.017 * * \\
(0.008)\end{array}$ & $\begin{array}{c}-0.017 * * \\
(0.008)\end{array}$ & $\begin{array}{r}-0.016 \\
(0.011)\end{array}$ & $\begin{array}{c}-0.017 * \\
(0.009)\end{array}$ \\
\hline Criminal family (childhood) & & & & $\begin{array}{c}-0.021 \\
(0.039)\end{array}$ & $\begin{array}{r}-0.020 \\
(0.030)\end{array}$ & $\begin{array}{c}-0.021 \\
(0.030)\end{array}$ & $\begin{array}{c}-0.034 \\
(0.042)\end{array}$ & $\begin{array}{r}-0.028 \\
(0.031)\end{array}$ & $\begin{array}{c}-0.028 \\
(0.031)\end{array}$ \\
\hline Parents separate (childhood) & & & & $\begin{array}{c}-0.021 \\
(0.032)\end{array}$ & $\begin{array}{r}-0.018 \\
(0.030)\end{array}$ & $\begin{array}{r}-0.017 \\
(0.030)\end{array}$ & $\begin{array}{r}-0.029 \\
(0.029)\end{array}$ & $\begin{array}{r}-0.023 \\
(0.029)\end{array}$ & $\begin{array}{c}-0.023 \\
(0.029)\end{array}$ \\
\hline Small municipality (childhood) & & & & $\begin{array}{c}-0.008 \\
(0.026)\end{array}$ & $\begin{array}{c}-0.005 \\
(0.025)\end{array}$ & $\begin{array}{c}-0.005 \\
(0.025)\end{array}$ & $\begin{array}{c}-0.008 \\
(0.025)\end{array}$ & $\begin{array}{c}-0.007 \\
(0.025)\end{array}$ & $\begin{array}{c}-0.007 \\
(0.024)\end{array}$ \\
\hline Criminal family members & & & & & & & $\begin{array}{l}0.070^{* *} \\
(0.033)\end{array}$ & $\begin{array}{c}0.059 * \\
(0.033)\end{array}$ & $\begin{array}{c}0.058^{*} \\
(0.033)\end{array}$ \\
\hline Criminal friends & & & & & & & $\begin{array}{l}0.110^{* * *} * \\
(0.032)\end{array}$ & $\begin{array}{l}0.093 \text { *** } \\
(0.024)\end{array}$ & $\begin{array}{l}0.092 * * * \\
(0.024)\end{array}$ \\
\hline Values: social contacts & & & & & & & $\begin{array}{l}-0.076^{* * * *} \\
(0.022)\end{array}$ & $\begin{array}{c}-0.074 * * * \\
(0.023)\end{array}$ & $\begin{array}{c}-0.073 * * * \\
(0.023)\end{array}$ \\
\hline Married & & & & & & & $\begin{array}{c}-0.031 \\
(0.030)\end{array}$ & $\begin{array}{c}-0.035 \\
(0.034)\end{array}$ & $\begin{array}{c}-0.035 \\
(0.034)\end{array}$ \\
\hline Frequent contact with partner & & & & & & & $\begin{array}{c}-0.056^{*} \\
(0.029)\end{array}$ & $\begin{array}{c}-0.055^{* *} \\
(0.024)\end{array}$ & $\begin{array}{c}-0.055^{* *} \\
(0.024)\end{array}$ \\
\hline Age & $\begin{array}{c}-0.001 \\
(0.002)\end{array}$ & $\begin{array}{c}-0.001 \\
(0.002)\end{array}$ & $\begin{array}{c}-0.001 \\
(0.001)\end{array}$ & $\begin{array}{c}-0.001 \\
(0.002)\end{array}$ & $\begin{array}{c}-0.001 \\
(0.002)\end{array}$ & $\begin{array}{c}-0.001 \\
(0.001)\end{array}$ & $\begin{array}{c}-0.000 \\
(0.002)\end{array}$ & $\begin{array}{c}-0.000 \\
(0.002)\end{array}$ & $\begin{array}{c}-0.001 \\
(0.002)\end{array}$ \\
\hline Male & $\begin{array}{c}0.062^{*} \\
(0.035)\end{array}$ & $\begin{array}{c}0.060 \\
(0.041)\end{array}$ & $\begin{array}{c}0.047^{*} \\
(0.028)\end{array}$ & $\begin{array}{c}0.060^{*} \\
(0.034)\end{array}$ & $\begin{array}{c}0.057 \\
(0.041)\end{array}$ & $\begin{array}{c}0.046 \\
(0.029)\end{array}$ & $\begin{array}{c}0.062^{*} \\
(0.035)\end{array}$ & $\begin{array}{c}0.057 \\
(0.040)\end{array}$ & $\begin{array}{c}0.050 \\
(0.033)\end{array}$ \\
\hline Nationality $=$ German & $\begin{array}{l}0.067 * * \\
(0.026)\end{array}$ & $\begin{array}{c}0.065 * \\
(0.035)\end{array}$ & $\begin{array}{c}0.063 * \\
(0.035)\end{array}$ & $\begin{array}{l}0.070^{* *} \\
(0.026)\end{array}$ & $\begin{array}{c}0.068 * \\
(0.036)\end{array}$ & $\begin{array}{c}0.065^{*} \\
(0.035)\end{array}$ & $\begin{array}{l}0.071 \text { *** } \\
(0.025)\end{array}$ & $\begin{array}{c}0.066^{*} \\
(0.035)\end{array}$ & $\begin{array}{c}0.065^{*} \\
(0.035)\end{array}$ \\
\hline Education $=$ Abitur & $\begin{array}{c}-0.044 \\
(0.034)\end{array}$ & $\begin{array}{c}-0.052 \\
(0.049)\end{array}$ & $\begin{array}{c}-0.055 \\
(0.048)\end{array}$ & $\begin{array}{c}-0.047 \\
(0.034)\end{array}$ & $\begin{array}{c}-0.055 \\
(0.049)\end{array}$ & $\begin{array}{c}-0.058 \\
(0.048)\end{array}$ & $\begin{array}{c}-0.029 \\
(0.034)\end{array}$ & $\begin{array}{r}-0.036 \\
(0.048)\end{array}$ & $\begin{array}{c}-0.037 \\
(0.048)\end{array}$ \\
\hline No professional education & $\begin{array}{c}-0.029 \\
(0.039)\end{array}$ & $\begin{array}{c}-0.031 \\
(0.027)\end{array}$ & $\begin{array}{c}-0.029 \\
(0.027)\end{array}$ & $\begin{array}{c}-0.027 \\
(0.040)\end{array}$ & $\begin{array}{c}-0.029 \\
(0.027)\end{array}$ & $\begin{array}{c}-0.027 \\
(0.027)\end{array}$ & $\begin{array}{c}-0.030 \\
(0.038)\end{array}$ & $\begin{array}{c}-0.033 \\
(0.027)\end{array}$ & $\begin{array}{c}-0.032 \\
(0.027)\end{array}$ \\
\hline Recidivist (prison sentence) & $\begin{array}{l}0.125^{* * * *} \\
(0.036)\end{array}$ & $\begin{array}{l}0.105 * * * \\
(0.027)\end{array}$ & $\begin{array}{l}0.106^{* * * *} \\
(0.026)\end{array}$ & $\begin{array}{l}0.127 * * * \\
(0.036)\end{array}$ & $\begin{array}{l}0.106^{* * * *} \\
(0.027)\end{array}$ & $\begin{array}{l}0.107 * * * \\
(0.027)\end{array}$ & $\begin{array}{l}0.121 \text { *** } \\
(0.035)\end{array}$ & $\begin{array}{l}0.101 * * * \\
(0.027)\end{array}$ & $\begin{array}{l}0.101 * * * \\
(0.026)\end{array}$ \\
\hline Age at first crime & $\begin{array}{c}-0.004 * * \\
(0.002)\end{array}$ & $\begin{array}{l}-0.006 * * * \\
(0.002)\end{array}$ & $\begin{array}{l}-0.005 * * * \\
(0.002)\end{array}$ & $\begin{array}{c}-0.004 * * \\
(0.002)\end{array}$ & $\begin{array}{l}-0.006^{* * *} * \\
(0.002)\end{array}$ & $\begin{array}{c}-0.006 * * * \\
(0.002)\end{array}$ & $\begin{array}{c}-0.003^{*} \\
(0.002)\end{array}$ & $\begin{array}{l}-0.005 * * * \\
(0.002)\end{array}$ & $\begin{array}{l}-0.004 * * * \\
(0.002)\end{array}$ \\
\hline Alcohol/drug addiction & $\begin{array}{l}0.161 * * * \\
(0.028)\end{array}$ & $\begin{array}{l}0.136^{* * * *} \\
(0.025)\end{array}$ & $\begin{array}{l}0.137 * * * \\
(0.025)\end{array}$ & $\begin{array}{l}0.163 * * * \\
(0.027)\end{array}$ & $\begin{array}{l}0.138 * * * \\
(0.025)\end{array}$ & $\begin{array}{l}0.139 * * * \\
(0.025)\end{array}$ & $\begin{array}{l}0.144 * * * \\
(0.025)\end{array}$ & $\begin{array}{l}0.119 * * * \\
(0.025)\end{array}$ & $\begin{array}{l}0.120 * * * \\
(0.025)\end{array}$ \\
\hline Crime $=$ theft & $\begin{array}{c}0.083^{*} \\
(0.041)\end{array}$ & $\begin{array}{l}0.068 * * \\
(0.030)\end{array}$ & $\begin{array}{l}0.068 * * \\
(0.029)\end{array}$ & $\begin{array}{c}0.082 * \\
(0.041)\end{array}$ & $\begin{array}{l}0.067 * * \\
(0.030)\end{array}$ & $\begin{array}{l}0.068 * * \\
(0.029)\end{array}$ & $\begin{array}{c}0.073 * \\
(0.040)\end{array}$ & $\begin{array}{l}0.058 * * \\
(0.029)\end{array}$ & $\begin{array}{l}0.059 * * \\
(0.029)\end{array}$ \\
\hline Crime $=$ drug deal $/$ consumption & $\begin{array}{c}0.095 * \\
(0.050)\end{array}$ & $\begin{array}{l}0.081 \text { *** } \\
(0.031)\end{array}$ & $\begin{array}{l}0.078 * * * \\
(0.030)\end{array}$ & $\begin{array}{c}0.097^{*} \\
(0.050)\end{array}$ & $\begin{array}{l}0.082 * * * \\
(0.031)\end{array}$ & $\begin{array}{l}0.080 * * * \\
(0.030)\end{array}$ & $\begin{array}{c}0.088^{*} \\
(0.048)\end{array}$ & $\begin{array}{l}0.076^{* *} \\
(0.030)\end{array}$ & $\begin{array}{l}0.074 * * \\
(0.030)\end{array}$ \\
\hline Crime $=$ fraud & $\begin{array}{c}0.042 \\
(0.033)\end{array}$ & $\begin{array}{c}0.037 \\
(0.031)\end{array}$ & $\begin{array}{c}0.038 \\
(0.031)\end{array}$ & $\begin{array}{c}0.042 \\
(0.034)\end{array}$ & $\begin{array}{c}0.037 \\
(0.031)\end{array}$ & $\begin{array}{c}0.038 \\
(0.031)\end{array}$ & $\begin{array}{c}0.047 \\
(0.034)\end{array}$ & $\begin{array}{c}0.042 \\
(0.031)\end{array}$ & $\begin{array}{c}0.043 \\
(0.031)\end{array}$ \\
\hline Crime $=$ assault & $\begin{array}{c}-0.005 \\
(0.050)\end{array}$ & $\begin{array}{c}-0.005 \\
(0.032)\end{array}$ & $\begin{array}{c}-0.005 \\
(0.032)\end{array}$ & $\begin{array}{r}-0.003 \\
(0.050)\end{array}$ & $\begin{array}{r}-0.003 \\
(0.032)\end{array}$ & $\begin{array}{r}-0.003 \\
(0.032)\end{array}$ & $\begin{array}{c}-0.010 \\
(0.048)\end{array}$ & $\begin{array}{r}-0.008 \\
(0.032)\end{array}$ & $\begin{array}{c}-0.008 \\
(0.032)\end{array}$ \\
\hline Crime $=$ sexual offense & $\begin{array}{c}0.011 \\
(0.041)\end{array}$ & $\begin{array}{c}0.012 \\
(0.044)\end{array}$ & $\begin{array}{c}0.012 \\
(0.043)\end{array}$ & $\begin{array}{c}0.014 \\
(0.041)\end{array}$ & $\begin{array}{c}0.015 \\
(0.044)\end{array}$ & $\begin{array}{c}0.015 \\
(0.043)\end{array}$ & $\begin{array}{c}0.027 \\
(0.038)\end{array}$ & $\begin{array}{c}0.027 \\
(0.043)\end{array}$ & $\begin{array}{c}0.028 \\
(0.043)\end{array}$ \\
\hline Crime $=$ murder & $\begin{array}{c}0.014 \\
(0.031)\end{array}$ & $\begin{array}{c}0.006 \\
(0.046)\end{array}$ & $\begin{array}{c}0.006 \\
(0.045)\end{array}$ & $\begin{array}{c}0.015 \\
(0.031)\end{array}$ & $\begin{array}{c}0.006 \\
(0.046)\end{array}$ & $\begin{array}{c}0.006 \\
(0.045)\end{array}$ & $\begin{array}{c}0.012 \\
(0.027)\end{array}$ & $\begin{array}{r}-0.002 \\
(0.046)\end{array}$ & $\begin{array}{c}-0.001 \\
(0.045)\end{array}$ \\
\hline Crime $=$ other crime & $\begin{array}{c}0.029 \\
(0.033)\end{array}$ & $\begin{array}{c}0.027 \\
(0.033)\end{array}$ & $\begin{array}{c}0.024 \\
(0.032)\end{array}$ & $\begin{array}{c}0.030 \\
(0.033)\end{array}$ & $\begin{array}{c}0.027 \\
(0.033)\end{array}$ & $\begin{array}{c}0.024 \\
(0.032)\end{array}$ & $\begin{array}{c}0.027 \\
(0.034)\end{array}$ & $\begin{array}{c}0.022 \\
(0.032)\end{array}$ & $\begin{array}{c}0.020 \\
(0.032)\end{array}$ \\
\hline Observations & 1124 & 1124 & 1124 & 1124 & 1124 & 1124 & 1124 & 1124 & 1124 \\
\hline Groups & 23 & 23 & 23 & 23 & 23 & 23 & 23 & 23 & 23 \\
\hline $\begin{array}{l}R^{2} / \chi^{2} \\
\mathrm{P}\left(\chi^{2}\right)\end{array}$ & 0.16 & $\begin{array}{c}158.08 \\
0.00\end{array}$ & $\begin{array}{c}208.92 \\
0.00\end{array}$ & 0.16 & $\begin{array}{c}158.66 \\
0.00\end{array}$ & $\begin{array}{c}206.41 \\
0.00\end{array}$ & 0.19 & $\begin{array}{c}184.71 \\
0.00\end{array}$ & $\begin{array}{c}209.30 \\
0.00\end{array}$ \\
\hline
\end{tabular}

Notes: The dependent variable is "assessment of recidivism". The reported values are the estimated APE, the numbers in parentheses are the standard errors adjusted for heteroscedasticity and clustering of prisons. GEE models assume binomial LEF, probit link function and exchangeable working correlation matrix. * significant at $10 \%$, ** significant at $5 \%, * * *$ significant at $1 \%$. 
Drago et al. (2011) and others, but they hint at the need for further research which focuses on the time span after release.

The pure size effect (aside from overcrowding) is rarely studied in criminometric studies. Farrington and Nuttal (1980) found that after controlling for overcrowding they showed that size had no significant influence. In our study prison size maintains a positive sign, also after controlling for overcrowding and several other factors. A ceteris paribus increase of 100 inmates would correspond to a small but significantly higher self-assessed likelihood of recidivism of plus one percent. It should be reminded that large prisons do not necessarily imply negative prison conditions when the number of prison staff and resources are proportional to the number of inmates. It should also be noted that we include the number of employees per prisoner as well as the prison-specific average size of a prison cell as explanatory group variables. So the positive effect of prison size might originate from something else, as, for instance, the higher degree of anonymity and isolation in big prisons. Moreover, even after controlling for type of crime and substance-use problems, it cannot be fully precluded that the positive sign might be affected by selecting crime-prone risk groups into large prisons.

The fourth and last prison factor refers to the quality of accommodation. We use the average size of a single-room cell as indicator and find that adverse prison conditions (small cells) increase self-assessed likelihood of recidivism. Thus the results regarding the effect of prison conditions are partly in line with previous findings that negative environments may even increase the likelihood of future reoffending. However, the deterrent effect of overcrowding on prisoners' expectations also demands for more research, which needs to focus on the lack of integration of criminals into society after release from prison.

Among the control variables, predictors of recidivism are consistent with past research and expectations, lending a high degree of confidence to methods and results presented in this paper. 'Male', and 'Alcohol/ Drug Addiction' have significant and positive effects on expereoffending. Among the types of crime, inmates committed for theft and illicit drug use or drug dealing show the highest rates of self-assessed likelihood of recidivism ${ }^{11}$. Also inmates with a former prison sentence expect higher rates of future recidivism. Their expected likelihood of future imprisonment is on average 10 to 12 percentage points higher than the one of first-time prisoners. Given socioeconomic status and prison characteristics, it is interesting to note that inmates of German nationality have higher rates of recidivism than non-Germans. Also the results covering social bonds and social capital seem plausible. Existence of criminal family members and peers is associated with higher probabilities of expected future reoffending, whereas frequent contact with partners and highly valued social contacts are negatively related to recidivism. Inmates who started their criminal career at an early stage of their life show higher persistency of offending behavior than

\footnotetext{
${ }^{11}$ Note that we experimented with the imposed length of prison terms as further explanatory variable. As length of imprisonment turned out to be insignificant and its missing data also caused a loss of about 400 observations, we do not report these results in the paper; they are available upon request.
} 
those who start later (see "age at first crime").

Coming back to the econometrics of grouped data used for the prison-prisoner data in this paper, one should finally mention an additional feature of grouped data different to classical panel settings: the assumptions of a small sample size and of a large number of clusters are rarely maintained for this type of the data. We frequently observe many individuals per cluster, while the number of clusters may be small. To correct the standard errors and related inference for this specific case methodologies proposed by Donald, Lang (2007) (adjusted T-distribution for the inference), Cameron et al. (2008) (wild-bootstrap-errors) or Wooldridge (2003, 2006) (minimum chi-square distance estimator) may be used. Cameron, Miller, $(2010,2015)$ and Angrist, Pischke (2009) discuss how big the number of clusters should be. Norton et al. (1996) showed that for consistent GEE estimation the number of clusters should at least exceed 10. Therefore the number of prisons in our sample (23) is considered to be sufficiently large.

\subsection{Analysis of potential self-selection problems}

Inmates with higher motivation and better abilities may more likely participate in the activities available in a prison. This may also influence the inmate's decision to participate in a survey, which, in turn, may lead to a self-selection bias of obtained estimates. Yet it should be taken into account that prison inmates were randomly assigned to participate in the survey by the researchers (let us assume $l_{g}$ to be the chosen participation assignment rate for prison $g$ ). Nevertheless, participants not necessarily show up on the day of the survey due to personal reasons. To ensure that the inmate's decision to participate in the survey is independent of his or her individual characteristics, we resort to Bayes' law. We derive the conditional distributions of participation rates across the prisons, and test the hypothesis that the participation rates are significantly different across various subgroups. For this reason, we explore the exogenous properties of prison administration data on the four following characteristics of the convicts at each prison: exposure to recidivism, alcohol addiction, drug addiction, employment status at the prison, and combine them with available information on the participants from the survey data. Let $\mathrm{D}$ be the dummy variable, which is set to 1 if an inmate possesses one of the four characteristics presented above, e.g. an inmate is a recidivist ${ }^{12}$. Participation is set to 1 if the convicted took part in the survey. After some elaboration on Bayes' law, conditional participation probabilities for each prison $g$ are as follows:

$$
\begin{gathered}
P_{g}(\text { Participation }=1 \mid D=1)=\frac{P_{g}(D=1 \mid \text { Participation }=1) \cdot P_{g}(\text { Participation }=1)}{P_{g}(D=1)}, \\
P_{g}(\text { Participation }=1 \mid D=0)=\frac{P_{g}(\text { Participation }=1)-P_{g}(D=1) \cdot P_{g}(\text { Participation }=1 \mid D=1)}{1-P_{g}(D=1)} .
\end{gathered}
$$

\footnotetext{
${ }^{12}$ The same procedure is applied to constructing conditional participation probabilities for the other three factors: alcohol addiction, drug addiction, employment status at the prison.
} 
Eq. (11) and Eq. (12) represent the probability of survey participation by recidivists and firsttime convicts, respectively. The computation of conditional and unconditional probabilities in the equations is based on the assumption that the prison administration data represents the population data, whereas the data on inmates is treated as a given subsample of this population. The key components of Eq. (11) and Eq. (12) are determined as follows:

$P_{g}(D=1) \quad=$ share of recidivists at prison $g$ (prison administration data)

$P_{g}(D=1 \mid$ Participation $=1) \quad=$ share of recidivists among participants at prison $g$ (individual data)

$P_{g}($ Participation $=1) \quad=\frac{\text { number of participants in the survey at prison } g \text { (individual data) }}{l_{g} \cdot \text { total number of prisoners at prison } g \text { (prison administration data) }}$

The formula for the participation probability $P_{g}($ Participation $=1)$ should be read as the share of the survey participants in the number of inmates, invited to take part in the survey. Therefore, an included constant $l_{g}$ reflects the previously mentioned random assignment of the prisoners to participate in the survey. Not all of the inmates took part in the survey, therefore, the participation rate has to be corrected by the constant $l_{g}$.

We compute the conditional participation probabilities using formulas in Eq. (11) and in Eq. (12). Table 3 contains descriptive information on computed conditional probabilities across different groups of inmates. At the descriptive level, the participation decision of a convict looks rather independent from his social background characteristics. Participation rates across different sub-groups (exposure to recidivism, alcohol addiction, drug addiction, employment status at the prison) only slightly differ from each other, the average participation rate across all the prisons amounts to $12 \%$.

Table 3: Participation rates. Descriptives across prisons.

\begin{tabular}{lccccc}
\hline & \# of prisons & Mean & SE & Min & Max \\
\hline$P($ Participation $=1 \mid$ Recidivism - Yes $)$ & 22 & 0.11 & 0.08 & .01671 & .28633 \\
$P($ Participation $=1 \mid$ Recidivism - No $)$ & 22 & 0.14 & 0.11 & .01086 & .51923 \\
$P($ Participation $=1 \mid$ Alcoholism - Yes $)$ & 22 & 0.17 & 0.18 & .01003 & .7874 \\
$P($ Participation $=1 \mid$ Alcoholism - No $)$ & 22 & 0.13 & 0.10 & .02614 & .38655 \\
$P($ Participation $=1 \mid$ Drug addiction - Yes $)$ & 23 & 0.09 & 0.08 & .00358 & .36765 \\
$P($ Participation $=1 \mid$ Drug addiction - No $)$ & 23 & 0.14 & 0.16 & .01661 & .82353 \\
$P($ Participation $=1 \mid$ Employment - Yes $)$ & 21 & 0.12 & 0.09 & .02242 & .36842 \\
$P($ Participation $=1 \mid$ Employment - No $)$ & 21 & 0.14 & 0.12 & .01762 & .5 \\
\hline$P($ Participation $=1)$ & 24 & 0.12 & 0.10 & .02716 & .40491 \\
\hline
\end{tabular}

Further we perform the two-sided t-test of equal means for two groups of equal size with unequal variances (Welch 1947). Testing $H_{0}: \mu_{1}=\mu_{2}$, where $\mu_{i}$ is a related mean of the group $i$, in our case translates into testing $H_{0}: \mu_{P(P \mid D)}=\mu_{P(P \mid \bar{D})}$. Fortunately, the exploited $l_{g}$ correction does not influence our testing decision. Both of the conditional probabilities, $P_{g}(P \mid D)$ and $P_{g}(P \mid \bar{D})$, are 
inflated by the same constant $1 / l_{g}$ through the multiplier in the nominator $P_{g}(P)$. See the following proof for the detail:

$$
P_{g}(P \mid \bar{D})=\frac{P_{g}(P \bar{D})}{P_{g}(\bar{D})}=\frac{P_{g}(\bar{D} \mid P) \cdot P_{g}(P)}{1-P_{g}(D)}=\frac{\left(1-P_{g}(D \mid P)\right) \cdot P_{g}(P)}{1-P_{g}(D)}
$$

where $P$ represents Participation $=1, D$ means $D=1$ and $\bar{D}$ represents $D=0$. Thus both probabilities can be compared and tested using the two-sided t-test.

Table 4: Indifference of Participation Rates across Different Subgroups of Convicted.

\begin{tabular}{llccccccc}
\hline & & Recidivism & \multicolumn{2}{c}{ Alcoholism } & \multicolumn{2}{c}{ Drug addiction } & \multicolumn{2}{c}{ Employment } \\
& & No & Yes & No & Yes & No & Yes & No \\
\hline Recidivism & Yes & 0.2968 & 0.1555 & 0.3709 & 0.5177 & 0.3391 & 0.5967 & 0.2359 \\
& No & & 0.5002 & 0.8728 & 0.1169 & 0.8849 & 0.5949 & 0.8335 \\
Alcoholism & Yes & & & 0.4250 & $0.0775^{*}$ & 0.6312 & 0.2844 & 0.6234 \\
& No & & & & 0.1499 & 0.7831 & 0.7079 & 0.7162 \\
Drug addiction & Yes & & & & & 0.1758 & 0.2647 & $0.0971^{*}$ \\
& No & & & & & & 0.5690 & 0.9716 \\
Employment & Yes & & & & & & 0.4755 \\
\hline
\end{tabular}

Notes: p-values for two-sided t-test of the hypothesis $H_{0}: \mu_{1}=\mu_{2}$, equivalence of mean values across two different subsamples with unequal variances.

The performed test confirms the conclusion that participation versus non-participation does not depend on personal characteristics, as already hypothesized at the descriptive level. Almost none of the p-values presented in Table 4 exceeds the $10 \%$ significance level. Thus, we are not able to reject the hypothesis of equality of participation rates across different subgroups of convicts, which, in turn, substantiates the hypothesis of random participation of inmates in the survey.

\section{Conclusion}

Attitudes, behavior, expectations and assessments of inmates and prison releases not only depend on individual characteristics but also on prison conditions. This paper presents econometric methods which help to analyze so called prison-prisoner data sets.

We simultaneously include characteristics of both matched prisons and prisoners which reduces the potential bias arising from omitting unobserved prison and prisoner characteristics in studies of recidivism. Unlike linked-employer-employee econometrics, realizations of prisonprisoner variables are not observed over time such that the elaborate least-squares framework approach based on "person" and "firm" effects proposed by Abowd et al. (1999) cannot be applied. Nevertheless, we argue that the inclusion of information on prisoners as well as on prisons, in which they are/were incarcerated, is still of crucial importance for consistent and efficient econometric estimation. The presented framework is based on the literature on "grouped data" (or "clustered data"). We adjust the methodology to available dichotomous data on recidivism tendencies and compare suitable random effects and GEE estimation techniques. It has been shown that the 
GEE methodology has some advantages as it provides the more robust estimator and also gains efficiency through the use of the working correlation matrix.

To substantiate and illustrate theoretical findings, we provide empirical evidence of the impact of prison conditions on prisoners' assessments of the future. This is of particular interest because while there seems to be a weak consensus that harsh experiences in prisons are negatively related to recidivism, there is no clear evidence whether the reasons lie in the fact of adverse prison conditions, or in the unpreparedness for life outside prison which eventually leads to frustration, strain and anger.

Using prison-prisoner data from Germany, prison conditions show significant effects. Among others, prison overcrowding is found to have a negative effect on the assessed likelihood one's own future reincarceration. This 'deterrent' effect of overcrowding is at odds with former results based on 'realized' recidivism. The result leads us to conclude that future research should focus more on 'perceived specific deterrence', which constitutes a missing link between prison conditions and crime rates of ex-inmates. It seems likely that 'outside factors' such as employment, peer influence and other post-release conditions are widely neglected in the interpretation of the relationship between prison conditions and recidivism.

This paper has some limitations that provide opportunities for future research. For instance, empirical evidence is based on longitudinal information gathered from a cross-sectional survey such that causal conclusions should be drawn with appropriate caution. Controlling for unobserved heterogeneity is a key issue when studying the treatment effect of prison conditions on future recidivism. Thus, future research would benefit from the application of register data that allows following individuals inside and outside (repeated) imprisonment. More evidence is also required on the evaluation of the compound link between conditions inside prisons and outside recidivism, and on the true effect of prison conditions, net of outside post-release influences. Understanding what happens after release, conditional on pre-release prison conditions, attitudes and aspirations, is neglected in research but of particular importance. The question of successful reintegration into society brings the evaluation of probation services into focus. Optimal research conditions would demand for combined longitudinal information on inmates, their prison conditions, rehabilitation services, outside conditions and the work of probation officers. 


\section{Bibliography}

Abowd, J. M., Kramarz, F., and Margolis, D. N. (1999). High wage workers and high wage firms. Econometrica, 67(2):251-333.

Andrews, M. J., Schank, T., and Upward, R. (2004). Practical estimation methods for linked employer-employee data. Discussion Papers, Friedrich-Alexander-University Erlangen-Nuremberg, Chair of Labour and Regional Economics, 29.

Angrist, J. D. and Pischke, J. S. (2009). Mostly harmless econometrics: An empiricist's companion. Princeton University Press, Princeton.

Avio, K. L. (1998). The economics of prisons. European Journal of Law and Economics, 6:143-175.

Cameron, A. C., Gelbach, J. B., and Miller, D. L. (2008). Bootstrap-based improvements for inference with clustered errors. Review of Economics and Statistics, 90(3):414-427.

Cameron, A. C. and Miller, D. L. (2010). Robust inference with clustered data. Handbook of Empirical Economics and Finance, Chapman $\mathcal{E}$ Hall/CRC, pages 1-28.

Cameron, A. C. and Miller, D. L. (2015). A practitioner's guide to cluster-robust inference. Journal of Human Resources, 50(2):317-372.

Cameron, A. C. and Trivedi, P. K. (2005). Microeconometrics: Methods and applications. Cambridge University Press, Cambridge and New York.

Cameron, A. C. and Trivedi, P. K. (2010). Microeconometrics using Stata. Stata Press, College Station, Tex., rev. edition.

Chen, M. K. and Shapiro, J. M. (2007). Do harsher prison conditions reuce recidivism? A discontinuity-based approach. American Law and Economics Review, 9(1):1-29.

Clark, A. E. (2003). Unemployment as a social norm: Psychological evidence from panel data. Journal of Labor Economics, 21(2):323-351.

Crépon, B. and Kramarz, F. (2002). Employed 40 hours or not employed 39: Lessons from the 1982 mandatory reduction of the workweek. Journal of Political Economy, 110(6):1355-1389.

DeJong, C. (1997). Survival analysis and specific deterrence: Integrating theoretical and empirical models of recidivism. Criminology, 35(4):561-576.

Donald, S. G. and Lang, K. (2007). Inference with difference-in-differences and other panel data. Review of Economics and Statistics, 89(2):221-233.

Drago, F., Galbiati, R., and Vertova, P. (2011). Prison conditions and recidivism. American Law and Economics Review, 13(1):103-130.

Durlauf, S. N. (2002). On the empirics of social capital. The Economic Journal, 112:459-479.

Durose, M. R., Cooper, A. D., and Snyder, H. N. (2014). Recidivism of prisoners released in 30 states in 2005 : Patterns from 2005 to 2010. U.S. Department of Justice, Office of Justice Programs, Bureau of Justice Statistics, April 2014.

Entorf, H. (2009). Crime and the labour market: Evidence from a survey of inmates. Journal of Economics and Statistics, 2-3:254-269.

Entorf, H. (2012). Expected recidivism among young offenders: Comparing specific deterrence under juvenile and adult criminal law. European Journal of Political Economy, 28(4):414-429.

Entorf, H., Meyer, S., and Moebert, J. (2008). Evaluation des Justizvollzugs: Ergebnisse einer bundesweiten Feldstudie. Physica-Verlag, Heidelberg.

Farrington, D. P. and Nuttall, C. P. (1980). Prison size, overcrowding, prison violence, and recidivism. Journal of Criminal Justice, 8(4):221-231.

Franklin, T. W., Franklin, C. A., and Pratt, T. C. (2006). Examining the empirical relationship between prison crowding and inmate misconduct: A meta-analysis of conflicting research results. Journal of Criminal Justice, 34(4):401412. 
Ghisletta, P. and Spini, D. (2004). An introduction to generalized estimating equations and an application to assess selectivity effects in a longitudinal study on very old individuals. Journal of Educational and Behavioral Statistics, 29(4):421-437.

Groshen, E. L. (1991). Sources of intra-industry wage dispersion: How much do employers matter? The Quarterly Journal of Economics, 106(3):869-884.

Hamermesh, D. S. (2007). Fun with matched firm employee data: progress and road maps. IZA Discussion Paper Series, No. 2580.

Jehle, J.-M., Albrecht, H.-J., Hohmann-Fricke, S., and Tetal, C. (2013). Legalbewährung nach strafrechtlichen sanktionen. eine bundesweite rückfalluntersuchung 2007 bis 2010 und 2004 bis 2010. Bundesministerium der Justiz.

Jehle J-M. (2009). Criminal Justice in Germany. Facts and Figures. the Federal Ministry of Justice, 5:Table 29b.

Katz, L., Levitt, S., and Shustorovich, E. (2003). Prison conditions, capital punishment, and deterrence. American Law and Economics Association, 5(2):318-343.

Kiefer, N. M. and Neumann, G. R. (1979). An empirical job-search model, with a test of the constant reservation-wage hypothesis. Journal of Political Economy, 87(1):89-107.

Liang, K.-Y. and Zeger, S. L. (1986). Longitudinal data analysis using generalized linear models. Biometrika, 73(1):13-22.

Listwan, S. J., Sullivan, C. J., Agnew, R., Cullen, F. T., and Colvin, M. (2013). The pains of imprisonment revisited: The impact of strain on inmate recidivism. Justice Quarterly, 30(1):144-168.

Mastrobuoni, G. and Terlizzese, D. (2014). Rehabilitating rehabilitation: Prison conditions and recidivism. EIEF Working Paper 13/14.

Nagin, D. S., Cullen, F. T., and Jonson, C. L. (2009). Imprisonment and reoffending. Crime and Justice, 38(1):115200.

Neuhaus, J. M., Kalbfleisch, J. D., and Hauck, W. W. (1991). A comparison of cluster-specific and populationaveraged approaches for analyzing correlated binary data. International Statistical Review / Revue Internationale de Statistique, 59(1):25-35.

Norton, E. C., Bieler, G. S., Ennett, S. T., and Zarkin, G. A. (1996). Analysis of prevention program effectiveness with clustered data using generalized estimating equations. Journal of Consulting and Clinical Psychology, 64(5):919926.

Oreopoulos, P. (2006). Estimating average and local average treatment effects of education when compulsory schooling laws really matter. The American Economic Review, 96(1):152-175.

Pogarsky, G. and Piquero, A. R. (2003). Can punishment encourage offending? Investigating the "resetting" effect. Journal of Research in Crime and Delinquency, 40(1):95-120.

Pritikin, M. (2008). Is prison increasing crime? Wisconsin Law Review, 2008:1049-1108.

Siegel, L. J. (2012). Criminology. Wadsworth, Cengage Learning, Belmont, Calif., 11th edition.

Stock, J. H. (2010). The other transformation in econometric practice: Robust tools for inference. Journal of Economic Perspectives, 24(2):83-94.

Sykes, G. M. (2007). The society of captives: A study of a maximum security prison. Princeton classic editions. Princeton University Press, Princeton, NJ, 1st princeton classic edition.

Visher, C. and Travis, J. (2003). Transitions from prison to community: Understanding individual pathways. Annual Review of Sociology, 29(1):89-113.

Welch, B. L. (1947). The generalization of 'student's' problem when several different population variances are involved. Biometrika, 34(1-2):28-35.

White, H. (1980). A heteroskedasticity-consistent covariance matrix estimator and a direct test for heteroskedasticity. Econometrica, 48(4):817-838.

Wooldridge, J. M. (2003). Cluster-sample methods in applied econometrics. American Economic Review, 93(2):133138. 
Wooldridge, J. M. (2006). Cluster-sample methods in applied econometrics: an extended analysis. Michigan State University. Unpublished Manuscript.

Wooldridge, J. M. (2010). Econometric analysis of cross section and panel data. MIT Press, Cambridge, Mass., 2nd edition.

Zorn, C. (2001). Generalized estimating equation models for correlated data: A review with applications. American Journal of Political Science, 45(2):470-490.

Zorn, C. (2006). Comparing GEE and robust standard errors for conditionally dependent data. Political Research Quarterly, 59(3):329-341. 